This is an open access article under the CC BY-NC-ND license (https://creativecommons.org/licenses/by-nc-nd/3.0/) Issue III, November 2020

ISSN 2707-9481

ISBN 978-601-323-207-2

https://doi.org/10.31643/2020.036

\begin{abstract}
Akmal Jumanazarov
Institute of General and Inorganic Chemistry of the Academy of Sciences of the Republic of Uzbekistan Email: ionxanruz@mail.ru

ORCID ID https://orcid.org/0000-0002-7004-6325
\end{abstract}

\author{
Vitaliy P. Guro \\ Institute of General and Inorganic Chemistry of the \\ Academy of Sciences of the Republic of Uzbekistan \\ Email: ionxanruz@mail.ru \\ ORCID ID https://orcid.org/0000-0001-5765-0408
}

\title{
Method of Extraction of Cadmium from Waste Cadmium Calcium Phosphate Catalyst
}

\begin{abstract}
JSC "NAVOIYAZOT" in the process of producing acetaldehyde uses the catalyst "Catalyst cadmium-calcium-phosphate (CCP-N)" TU 113-03-00209510-108-2006, at a temperature of 340-350 ${ }^{\circ} \mathrm{C}$ and a pressure of 0.2- 5-0.7 atm. Its service life is 6 months, after which it must be replaced and stored. Meanwhile, it is a potential raw material for the synthesis of a new catalyst. Due to the toxicity of the component, there are practically no publications on the topic of its recycling, processing and production of CCP-N are highly specialized. However, the authors had previously managed to independently solve this problem, a necessary stage of their research was the testing of their own development in production - in JSC "NAVOIYAZOT". Purpose of the work: testing the developed method for extracting cadmium from spent cadmium-calcium-phosphate catalyst. The cadmium recovered from the spent CCP-N catalyst was sorbed on the $\mathrm{C}-100$ Purolite resin. Control of the content of components: $\mathrm{CdO}, \mathrm{CaO}$, and $\mathrm{P}_{2} \mathrm{O}_{5}$ was carried out on an ICP spectrometer Aligent 7500 ICP MS. Information was obtained on the yield of the product of processing the solubility of CCP-N, the efficiency of the selected precipitant of cadmium ions, and their sorption on the C-100 Purolite resin. The test result is positive. The effectiveness of the developed method for extracting cadmium was confirmed, with the registration of an application for a patent for it.
\end{abstract}

Keywords: cadmium, catalyst, precipitation, sorption, technology.

Cite this article as: Jumanazarov A., Guro V. P. (2020). Sposob izvlecheniya kadmiya iz otrabotannogo kadmiy-kal'tsiy-fosfatnogo katalizatora [Method of Extraction of Cadmium from Waste Cadmium Calcium Phosphate Catalyst]. Challenges of Science. Issue III, p.: 224-228. (In Russian). https:// doi.org/10.31643/2020.036

Акмаль Джуманазаров

Институт общей и неорганической химии

Академии наук Республики Узбекистан

Email: ionxanruz@mail.ru

ORCID ID https://orcid.org/0000-0002-7004-6325
Виталий П. Гуро

Институт общей и неорганической химии Академии наук Республики Узбекистан

Email: ionxanruz@mail.ru

ORCID ID https://orcid.org/0000-0001-5765-0408

\section{Способ извлечения кадмия из отработанного кадмий-кальций-фосфатного катализатора}

\footnotetext{
Абстракт. В AO «NAVOIYAZOT» в процессе получения ацетальдегида используется катализатор «Катализатор кадмий-кальций-фосфатный (ККФ-Н)» ТУ 113-03-00209510-108-2006, при температуре 340-350 ${ }^{\circ} \mathrm{C}$ и давлении 0,2-5-0,7 атм. Его срок службы - 6 мес., после чего он подлежит замене и складированию. Между
} 
тем, он представляет собой потенциальное сырье синтеза нового катализатора. Ввиду токсичности компонента, публикации по теме его рецайклинга практически отсутствуют, переработка и производство ККФ-Н высоко специализированы. Однако, авторам удалось ранее самостоятельно решить эту задачу, необходимым этапом их исследования стало испытание собственной разработки на производстве - в AO «NAVOIYAZOT». Цель paботы: испытание разработанного способа извлечения кадмия из отработанного кадмий-кальций-фосфатного катализатора. Кадмий, извлеченный из отработанного ККФ-Н катализатора, сорбировали на смоле С-100 Purolite. Контроль содержания компонентов: $\mathrm{CdO}, \mathrm{CaO}$ и $\mathrm{P}_{2} \mathrm{O}_{5}$ выполняли на ICP-спектрометре Aligent 7500 ICP MS. Получены сведения о выходе продукта переработки растворимости ККФ, эффективности выбранном осадителе ионов кадмия, сорбции их на смоле C-100 Purolite. Результат испытания положительный. Подтверждена эффективность разработанного способа извлечения кадмия, с оформлением заявка на выдачу патента на него.

Ключевые слова: кадмий, катализатор, осаждение, сорбция, технология.

\section{Введение}

В процессе получения ацетальдегида используется катализатор «Катализатор кадмийкальций-фосфатный (ККФ-Н)» ТУ 113-03-00209510-108-2006, при температуре 340-350 ${ }^{\circ} \mathrm{C}$ и давлении 0,2-5-0,7 атм., срок службы которого до 6 мес., после чего он подлежит замене и складированию. Между тем, он является потенциальным сырьем синтеза катализатора ККФ-Н. Публикации по теме его переработки немногочисленны, В республике этой темой ранее не занимались. Проводимое исследование [1] позволило предложить способ его переработки, завершающим его этапом стало испытание разработки в AO «NAVOIYAZOT».

Цель: испытание разработанного способа извлечения кадмия из отработанного кадмийкальций-фосфатного катализатора в AO «NAVOIYAZOT».

В основу способа переработки катализатора ККФ-Н положен опыт гидрометаллургии в этой области. Кроме того, приняты к рассмотрению альтернативные подходы: электромембранный электролиз [2], экстракция серной кислотой [3-5], адсорбционный метод [6].

\section{Методы и материалы}

Содержания $\mathrm{CdO}, \mathrm{CaO}$ и $\mathrm{P}_{2} \mathrm{O}_{5}$ в отработанном ККФ-Н катализаторе контролировали $\mathrm{AAC}-$ спектрометром Perkin-Elmer 3030B, Пробы катализатора растворяли в кислотах, отделяли осадок примесей. Сорбцию катионов вели на смоле С $100 \mathrm{H}$ Purolite. Чистоту извлеченного кадмия, каталитическую активность синтезированного ККФ-Н, прочность гранул, заключение об эффективности способа проводили в АО «Навоиазот».

\section{Результаты и обсуждение}

Испытание способа извлечения и рецайклинга кадмия из отработанного ККФ-Н катализатора проводили в АО «Навоиазот». На 1-м провели переработку ККФ-Н на кадмий [7]. Для этого 1,0 кг отработанного катализатора ККФ измельчали в шаровой мельнице до тонины 0,1 мм, растворяли в 10 л $\mathrm{HNO}_{3}$ (1:1). Нерастворившуюся часть (уголь) отфильтровывали. Очистку раствора от ионов Са(II) проводили следующим образом: раствор нейтрализовали $30 \% \mathrm{NaOH}$ до $\mathrm{pH} \sim 0$, нагревали до кипения, затем добавляли стехиометрическое количество $\mathrm{Na}_{2} \mathrm{SO}_{4}$ сульфата натрия (990 г) для осаждения сульфата кальция по реакции:

$$
\mathrm{Ca}\left(\mathrm{NO}_{3}\right)_{2}+\mathrm{Na}_{2} \mathrm{SO}_{4}=\mathrm{CaSO}_{4}+2 \mathrm{NaNO}_{3}
$$

Осадок сульфата кальция оставляли на 3 ч для «созревания» осадка и отфильтровывали. При этом осаждалось 90-95\% кальция, а концентрации ионов $\mathrm{Cd}(\mathrm{II})$ в растворах до и после отделения кальция была постоянной. Фильтрат нейтрализовывали гидроксидом натрия до $\mathrm{pH}$ 6-7 по реакции:

$$
\mathrm{Cd}\left(\mathrm{NO}_{3}\right)_{2}+2 \mathrm{NaOH}=\mathrm{Cd}(\mathrm{OH})_{2}+2 \mathrm{NaNO}_{3}
$$

Выпавший осадок гидроксида кадмия (включавщий фосфат кальция) отфильтровывали, 
промывая деионизированной водой для удаления нитрат-ионов и растворяли в 10 л раствора серной кислоты (98 г/л) по реакции:

$$
\mathrm{Cd}(\mathrm{OH})_{2}+\mathrm{H}_{2} \mathrm{SO}_{4}=\mathrm{CdSO}_{4}+2 \mathrm{H}_{2} \mathrm{O}
$$

Раствор фильтровали для отделения от фосфата кальция. Для устранения примеси раствор пропускали через колонну с катионитом Purolite $\mathrm{C}-100$ в $\mathrm{H}^{+}$-форме со скоростью 2-3 объема колонки в час (объем смолы 2,0 л). Степень сорбции 99,9\%, затем колонки промывали до рН 7, кадмий десорбировали 6-ю объемами $\mathrm{HCl}$ (72 г/л). Степень десорбции 98\%, а общего извлечения $\mathrm{Cd} 95$ \%.

Принципиальная технологическая схема переработки отработанного катализатора ККФ приведена в [8]. Состав исходного отработанного катализатора ККФ-Н, мг/г: Cd 100,13; Са 294,336; Р 156,467. По схеме, в ЦЛ АO «NAVOIYAZOT» применена лабораторная установка очистки [9].

Использовали в качестве сырья пробу отработанного ККФ-катализатора АО «Навоиазот» массой 1000 г. Из нее извлечено около 250 г Сd в форме $\mathrm{CdCl}_{2}$, с переводом соли в оксид $\mathrm{CdO}$.

На 2-м этапе работы, завершившемся 11.02.2020 в АО «Навоиазот», предварительно, из выделенного оксида кадмия и доступных локализованных химических реагентов синтезирована каталитическая масса ККФ-Н (рецайклинг), включающая оксиды и фосфаты кадмия и кальция. Ее состав соответствовал требованиям ТУ 113-03-00209510-108-2006 (табл. 1 и 2).

Таблица 1 - Соответствие состава катализатора ККФ требованиям

\begin{tabular}{lrc}
\hline Доля соединения в & $\begin{array}{c}\text { Требования ТУ 113-03-00209510-108-2006 к } \\
\text { ККФ, \% }\end{array}$ & $\begin{array}{c}\text { Состав синтезированного образца } \\
\text { составу ККФ, \% }\end{array}$ \\
\hline оксид кальция & $42,0-47,0$ & $46 \pm 1,5$ \\
\hline оксид кадмия & $10,0-13,0$ & $12 \pm 1,0$ \\
\hline оксид фосфора $\left(\mathrm{P}_{2} \mathrm{O}_{5}\right)$ & $40,0-47,0$ & $45 \pm 2,5$ \\
\hline
\end{tabular}

Таблица 2 - Технические показатели катализатора ККФ

\begin{tabular}{lc}
\hline \multicolumn{1}{c}{ Наименование показателя } & Значение показателя \\
\hline 1 Внешний вид & $\begin{array}{l}\text { Цилиндрические таблетки } \\
\text { серого цвета }\end{array}$ \\
2 Размеры, мм & $6,0 \pm 1,0$ \\
$\quad$ диаметр & $5,0 \pm 1,0$ \\
$\quad$ высота & $1,15-1,35$ \\
3 Насыпная плотность, кг/ дм ${ }^{3}$ & \\
4 Механическая прочность - разрушающее усилие при & \\
раздавливании по образующей, МПа, не менее & 3,0 \\
средняя & 2,0 \\
минимальная & \\
5 Массовая доля потерь катализатора при прокаливании при & 9,0 \\
температуре $750{ }^{\circ}$ С, \%, не более & $2,8 \pm 0,2$ \\
6 Молярное соотношение $\frac{C a O+C d O}{P_{2} O_{5}}$ & 2,0 \\
7 Массовая доля мелочи, \%, не более & \\
\hline
\end{tabular}

Затем эта масса была передана в АО «Максам-Чирчик», где в ее состав введено до 1 \% масс. углерода, и на пресс-автомате из смеси изготовлены таблетки катализатора ККФ-Н. Полученные образцы опытных партий переданы в АО «Навоиазот», где проведено испытание их каталитической активности в процессе синтеза ацетальдегида на лабораторной установке, размещенной на отм. 0.00 корпуса 650 цеха 007 АО «Навоиазот», руководствуясь инструкцией 33-ПЦ-6 по эксплуатации установки по испытанию катализатора ККФ-Н. Они показали достаточно высокую селективность и производительность по ацетальдегиду (табл. 3). Эти показатели удовлетворили технические службы предприятия, с возможностью дальнейшей модернизации технологии их получения на предприятии. 
Таблица 3 - Результат испытания образцов синтезированных ККФ-Н

\begin{tabular}{cc}
\hline Селективность по ацетальдегиду & Производительность по ацетальдегиду \\
\hline Средняя 73,28\% & Средняя $33,98 \mathrm{mg} / \mathrm{cm}^{3} \bullet \mathrm{h}$,
\end{tabular}

Ввиду ограниченного ресурса импортного ККФ-Н катализатора, в настоящее время он выводится из эксплуатации ежегодно в значительном количестве, из-за потери активности за счет накопления на поверхности «каталитических ядов», преимущественно соединений серы. Отходы, при длительном хранении, создают риск угрозы здоровью людей и окружающей среде, в связи с содержанием высокотоксичных соединений кадмия. Которые в экстремальных условиях могут попадать в грунтовые воды, почву и т.д. Напротив, налаживание переработки отработанного ККФ-Н катализатора дает экономический эффект от его рецайклинга, создает безотходную технологию каталитического синтеза ацетальдегида в АО «Навоиазот».

В предложенном способе, в качестве выщелачивающего агента гидрохимической переработки использована азотная кислота, проведено отделение от раствора осадка твердофазного углерода, а затем осуществлены операции, приведшие к получению целевого продукта - чистой соли или оксида кадмия. Согласно ему, ККФ-Н отход измельчают в шаровой мельнице до диаметра частиц 0,1 мм, порошок растворяют в азотной кислоте (1:1), отделяют от целевого продукта $\mathrm{CdCl}_{2}$, углерод, соединения кальция и фосфатов, процесс осуществляют в несколько стадий. Изучено влияния $\mathrm{pH}$ раствора осаждения Сd на извлечение (табл. 4).

Таблица 4 - Примеры влияния $\mathrm{pH}$ раствора осаждения $\mathrm{Cd}$ на извлечение

\begin{tabular}{cc}
\hline $\mathrm{pH}$ & Степень извлечения Сd из отработанного ККФ-катализатора, \% \\
\hline 5,8 & 76 \\
\hline 6,0 & 79 \\
\hline 6,5 & 85 \\
\hline 7,5 & 97 \\
\hline 8,0 & 90 \\
\hline 8,8 & 70 \\
\hline
\end{tabular}

Цепочка технологических операций позволяет получить хлорид кадмия с выходом 95-100\%. Последовательная очистка его от примесей - углерода, ионов Са(II), фосфат-ионов, обеспечивает максимально полное извлечение кадмия - сырья синтеза ККФ-катализатора. Суммарная продолжительность всех операций - составляет 3 ч, что быстрее, чем в прототипе и аналогах, в предлагаемом техническом решении, после выщелачивания в кислоте, решается вопрос отделения кадмия от примесных кальция и фосфатов.

\section{Выводы}

Разработан и успешно испытан в АО «Навоиазот» способ селективного извлечения кадмия из отработанного катализатора ККФ в виде солянокислой соли, пригодной для повторного использования (рецайклинга) в синтезе ККФ катализатора. Успешно испытана технология синтеза из выделенного кадмия нового работоспособного активного катализатора ККФ-Н.

Ссылка на данную статью: Джуманазаров А., Гуро В. П. (2020) Способ извлечения кадмия из отработанного кадмий-кальций-фосфатного катализатора. Материалы Международной практической интернет-конференции «Актуальные проблемы науки» [Challenges of Science]. Выпуск III, стр. 224-228. https://doi.org/10.31643/2020.036

\section{Литературы}

[1] Гуро, В. П., Ибрагимова, М. А., Дадаходжаев, А.Т., Сафаров, Е. Т., Фузайлова, Ф. Н. (2019). Переработка отработанного кадмий-кальций-фосфатного катализатора. Узбекский химический журнал. 3, (8-14). 
[2] Gouvea, Ligiane R., Morais, Carlos A. (2007). Recovery of zinc and cadmium from industrial waste by leaching/cementation. Minerals Engineering, Volume 20, Issue 9, August, Pages 956-958. https://doi.org/10.1016/j.mineng.2007.04.016

[3] Nogueira, C.A., Delmas, F. (1999)/ New flowsheet for the recovery of cadmium, cobalt and nickel from spent Ni-Cd batteries by solvent extraction. Hydrometallurgy Volume 52, Issue 3, June, Pages 267-287, https://doi.org/10.1016/S0304386X(99)00026-2

[4] Singh, Nagpur Navneet. (2014). Recovery of metals from spent nickel-cadmium (Ni-Cd) battery by leaching-electrowining process. Internal Conference on Nonferrous Metals-2014, Nagpur City (INDIA), July 2014.

[5] Ewa Rudnik, Marek Nikiel (2007). Hydrometallurgical recovery of cadmium and nickel from spent Ni-Cd batteries. Hydrometallurgy, V. 89, Issues 1-2, Sept., P. 61-71, https://doi.org/10.1016/j.hydromet.2007.05.006

[6] Karuppanna, P., Chinnaiya, N. (2008). Process Development for Removal and Recovery of Cadmium from Wastewater by a Low-Cost Adsorbent: Adsorption Rates and Equilibrium Studies. Ind. Eng. Chem. Res. 33, 2, 317-320, DOI: 10.1021/ie00026a022

[7] Ибрагимова, М.А., Ляпин, С.Б., Жуманазаров, А.Р., Гуро, В.П., Дадаходжаев, А.Т. (2019). Заявка на патент UZ IAP 20190251 от 10.06.2019. Способ извлечения кадмия из отработанного кадмий-кальций-фосфатного катализатора.

[8] Ибрагимова, М. А., Ляпин, С. Б., Жуманазаров, А. Р., Гуро, В. П., Дадаходжаев, А. Т. (2020). Испытание способа извлечения кадмия из отработанного кадмий-кальций-фосфатного катализатора // Узбекский химический журнал. 2.(24-30).

[9] Ляпин, С.Б., Ибрагимова, М.А., Гуро, В.П., Жуманазаров, А.Р. (2020). Очистка технологичеких растворов переработки отработанного катализатора ККФ от примесей фосфат-ионов методом ионного обмена. Узбекский химический журнал. 5, (44-48).

\section{References}

[1] Guro, V. P., Ibragimova, M. A., Dadakhodzhayev, A.T., Safarov, Ye. T., Fuzaylova, F. N. (2019). Pererabotka otrabotannogo kadmiy-kal'tsiy-fosfatnogo katalizatora [Recycling of spent cadmium-calcium-phosphate catalyst]. Uzbekskiy khimicheskiy zhurnal. 3, (8-14). (In Russian).

[2] Gouvea, Ligiane R., Morais, Carlos A. (2007). Recovery of zinc and cadmium from industrial waste by leaching/cementation. Minerals Engineering, Volume 20, Issue 9, August, Pages 956-958. https://doi.org/10.1016/j.mineng.2007.04.016 (In English).

[3] Nogueira, C.A., Delmas, F. (1999)/ New flowsheet for the recovery of cadmium, cobalt and nickel from spent Ni-Cd batteries by solvent extraction. Hydrometallurgy Volume 52, Issue 3, June, Pages 267-287, https://doi.org/10.1016/S0304386X(99)00026-2. (In English).

[4] Singh, Nagpur Navneet. (2014). Recovery of metals from spent nickel-cadmium (Ni-Cd) battery by leaching-electrowining process. Internal Conference on Nonferrous Metals-2014, Nagpur City (INDIA), July 2014. (In English).

[5] Ewa Rudnik, Marek Nikiel (2007). Hydrometallurgical recovery of cadmium and nickel from spent Ni-Cd batteries. Hydrometallurgy, V. 89, Issues 1-2, Sept., P. 61-71, https://doi.org/10.1016/j.hydromet.2007.05.006 (In English).

[6] Karuppanna, P., Chinnaiya, N. (2008). Process Development for Removal and Recovery of Cadmium from Wastewater by a Low-Cost Adsorbent: Adsorption Rates and Equilibrium Studies. Ind. Eng. Chem. Res. 33, 2, 317-320, DOI: 10.1021/ie00026a022 (In English).

[7] Ibragimova, M.A., Lyapin, S.B., Zhumanazarov, A.R., Guro, V.P., Dadakhodzhayev, A.T. (2019). Zayavka na patent UZ IAP 20190251 ot 10.06.2019. Sposob izvlecheniya kadmiya iz otrabotannogo kadmiy-kal'tsiy-fosfatnogo katalizatora [Method for recovering cadmium from spent cadmium-calcium-phosphate catalyst]. (In Russian).

[8] Ibragimova, M. A., Lyapin, S. B., Zhumanazarov, A. R., Guro, V. P., Dadakhodzhayev, A. T. (2020). Ispytaniye sposoba izvlecheniya kadmiya iz otrabotannogo kadmiy-kal'tsiy-fosfatnogo katalizatora [Testing a method for extracting cadmium from spent cadmium-calcium-phosphate catalyst] // Uzbekskiy khimicheskiy zhurnal. 2.(24-30). (In Russian).

[9] Lyapin, S.B., Ibragimova, M.A., Guro, V.P., Zhumanazarov, A.R. (2020). Ochistka tekhnologichekikh rastvorov pererabotki otrabotannogo katalizatora KKF ot primesey fosfat-ionov metodom ionnogo obmena [Purification of technological solutions for processing spent catalyst KKF from impurities of phosphate ions by the method of ion exchange]. Uzbekskiy khimicheskiy zhurnal. 5, (44-48). (In Russian). 